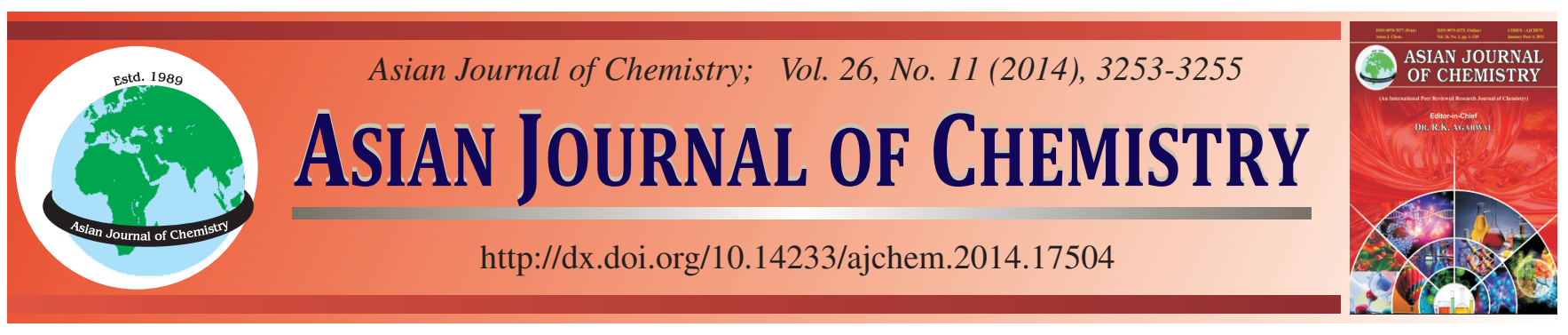

\title{
Effects of Microbe Concentration and Operation Conditions on Membrane Fouling in Treating Mustard Tuber Wastewater by Membrane Bioreactor
}

\author{
HongXiang Chai ${ }^{1,2,}$, Limin Li ${ }^{1,2}$, Yinghua Wei $^{1,2}$, Jun Du $^{1,2}$, JiAn Zhou $^{1,2}$ and Qiang He ${ }^{1,2}$
}

${ }^{1}$ Key Laboratory of the Three Gorges Reservoir Region's Eco-Environments, Ministry of Education, Chongqing University, Chongqing 400045, P.R. China

${ }^{2}$ National Centre for International Research of Low-Carbon and Green Buildings Chongqing University, Chongqing 400045, P.R. China

*Corresponding author: Tel/Fax: +86 23 65120980; E-mail: chaihx@cqu.edu.cn

Received: 3 February 2014;

Accepted: 5 April 2014;

Published online: 25 May 2014;

AJC-15226

\begin{abstract}
Membrane fouling is always the main hinderance in development and widespread application of membrane bioreactor (MBR). Microbe concentration and operation conditions were the main factors lead to membrane fouling including trans-membrane pressure (TMP), suction and cease time of the sorption pump, activated sludge concentration (MLSS). Four phases of operating conditions were carried out to investigate the decline rate and trend of the membrane flux and the influence on membrane fouling, finally find out the most effective parameters in treating mustard wastewater. Results showed that when the trans-membrane pressure, suction time, cease time and MLSS were $15 \mathrm{kpa}, 10 \mathrm{~min}, 3 \mathrm{~min}, 6000 \mathrm{mg} / \mathrm{L}$, respectively, the membrane bioreactor ran steadily and the flux decline velocity was low.
\end{abstract}

Keywords: Membrane fouling, Membrane flux, Trans-membrane pressure, Cease time, MLSS.

\section{INTRODUCTION}

Membrane bioreactor (MBR) also called membrane separation of activated sludge, which was first appeared in $1960 \mathrm{~s}^{1}$ and now applied in the whole world. Despite the fact that the type of the sewage and the process of the MBR varies widely, all MBR processes can achieve a high quality effluent. The MBR process can overcome the disadvantages of sludge bulking and unstable effluent. The process has many potential advantages ${ }^{2,3}$. While MBR has many advantages, membrane fouling is unavoidable, although it can be reduced to a certain degree by adopting pretreatment processes and various membrane fouling control strategies and noxious to the efficiency of RO processes on account of it reduces water production and finally increases energy consumption ${ }^{4}$. Generally membrane fouling also deteriorates product water quality ${ }^{5-7}$ because of enhanced concentration polarization ${ }^{8-11}$, while exception could occur ${ }^{12}$ and the extent depends upon the characteristics of fouling layer ${ }^{13}$. Membrane materials ${ }^{14-16}$, characteristics of the mixture ${ }^{17-19}$ and operation conditions are three main elements affect membrane fouling. Results ${ }^{20}$ showed that the membranes biofoul tendency depended upon the properties of the activated sludge in the MBR systems and depended on operating conditions as well, which including trans-membrane pressure, permeate flux, quality of influent, dissolved oxygen, cease time, temperature, reactor structure and so on.
Howell ${ }^{21}$ put forward the concept of critical membrane flux, when the membrane flux was more than critical membrane flux, trans-membrane pressure ramped and the degree of membrane fouling were enhanced at the same time. But when membrane flux was lower than critical membrane flux, the MBR could work more stably and membrane flux declined slowly. Chang and Judd $^{22}$ compared the effluence of the jet aeration and gas lift aeration on membrane fouling and found that the membrane flux of jet aeration is $12 \%$ times higher than gas lift aeration when the membrane pipe were not polluted. But as soon as the pipes were polluted, the flux decline rate was higher under the condition of jet aeration than the gas lift aeration. Gui et al. ${ }^{23}$ study the influence of aeration intensity, initial membrane flux and the suction and cease time on membrane fouling. Results of the test showed that the membrane flux under the condition of critical membrane flux can efficiently slow down membrane pollution, but when sludge concentration is high, aeration intensity greatly influence membrane fouling and the suction and cease time effect membrane fouling simultaneously. Cao et $a l .{ }^{24}$ analyzed the effects of the MBR operations on membrane pollution and the results revealed that decreasing boundary layer thickness, shorting membrane silk diameter and increasing per unit length of membranemodules could slow down the velocity of membrane fouling when the suction time is $10 \mathrm{~min}$ and cease time is $2 \mathrm{~min}$. 
The mustard tuber wastewater was high in salinity and thus increased the degree of membrane fouling. The effects of single operation condition on the membrane fouling were studied with an emphasis on finding the optimal parameters and then provide a guideline for the operation.

\section{EXPERIMENTAL}

Flow diagram of the test is shown in Fig. 1. This test used aerobic biofilm-membrane bioreactor, size of it was $1.08 \mathrm{~m} \times$ $0.75 \mathrm{~m} \times 0.6 \mathrm{~m}$ (length $\times$ width $\times$ height $)$, effective water depth was $0.5 \mathrm{~m}$, effective volume was $0.4 \mathrm{~m}^{3}$. The experimental wastewater used in this test was from the composite wastewater provided by Fuling Mustard Tuber Group Go Ltd Chongqing China. The wastewater quality is listed in Table-1.

General procedure: The experiment was divided into four stages. Three groups of reactors were used in experiment 1 for comparison and the trans-membrane pressure (TMP) were controlled at 10, 15 and $20 \mathrm{kpa}$, respectively. Experiment 2 adopt the method of fixing filtration time and extending cease time relatively to investigate the influence on the membrane fouling. The conditions were controlled as suction time of the four groups was $10 \mathrm{~min}$ and the cease time was $0,1,3$ and 5 min, respectively. TMP was controlled at $15 \mathrm{kpa}$. Experiment 3 was carried out under the following experimental conditions: $\mathrm{TMP}=15 \mathrm{kpa}$, cease time $=3 \mathrm{~min}$ and the MLSS concentration were controlled at 2000, 4000 and $6000 \mathrm{mg} / \mathrm{L}$, respectively. The text indexes during experiments were membrane flux.

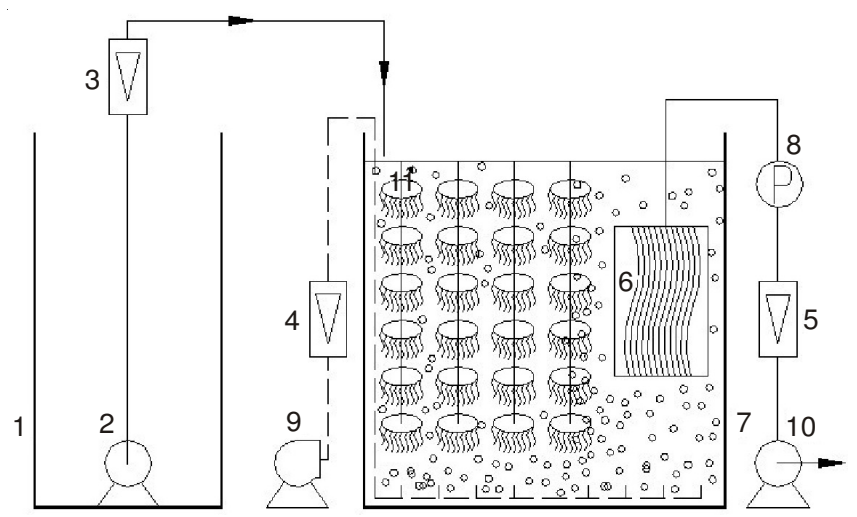

Fig. 1. Flow diagram of the test. 1 regulating reservoir, 2 inlet pump, 3-5 flowmeter, 6 membrane module, 7 mixed MBR, 8 pressure gage, 9 air pump, 10 suction pump, 11 biological membrane packing

\section{RESULTS AND DISCUSSION}

The results of the test about the effect of TMP on membrane fouling were shown in Fig. 2. Thus, the higher the TMP was the greater the initial membrane flux would be. The membrane flux reduction rate was bigger with it. A comparison of these effects normalized to membrane resistance and flux showed that concentration of polarization (CP) was usually the primary parameter to affect the flux decline and caused pronounced impacts as the feed water ionic strength increased ${ }^{25}$.

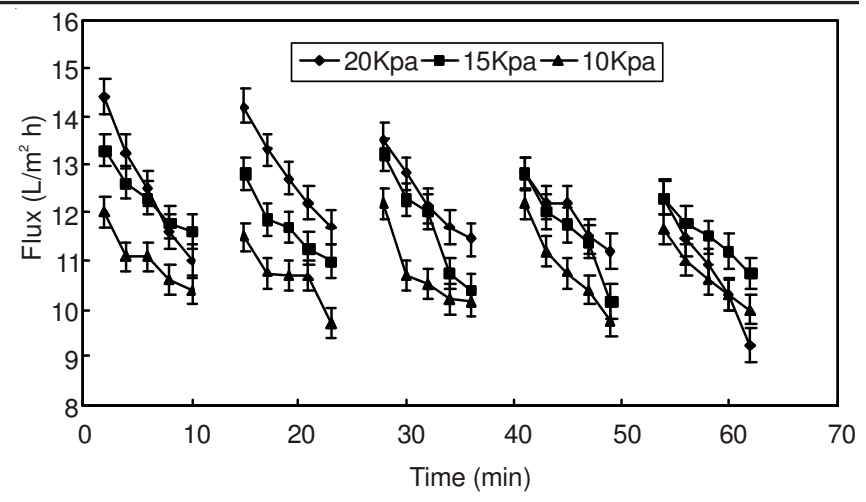

Fig. 2. Effect of TMP on membrane fouling

According to the theory of concentration of polarization, when TMP was higher, solid particle in sludge mixture were driven by pressure, velocity of transmission to the membrane surface was higher than the inversion. Thus gel layer became thicker and filtration resistance increased, membrane flux became more and more small. So the cake layer filtration had a dominant position. When TMP was lower, the rate and degree formed by concentration polarization decrease as well. At the same time, filtration resistance was low and membrane filtration took the dominant position. Hence comprehensive consideration of the degree of membrane pollution and operation cost, $\mathrm{TMP}=15 \mathrm{kpa}$ was the most efficiency operation pressure.

Different cease time the membrane flux: Membrane fouling was due to the higher adhesion rate of the contaminants on membrane surface over the shedding rate. Membrane contaminants attachment rate could be decreased effectively by the means of extend aeration time relatively. Longer the air aeration time was, faster the detachment rate of the deposited sludge on the membrane would be and the filtration performance of membrane recovered more ${ }^{26}$.

Fig. 3 depicted that membrane flux decline continuously without any cease time but adding cease time per unit can recover the membrane flux to some degree, when ceasing time changed from 0 to $1,3,5$ the membrane flux increased to some extent.

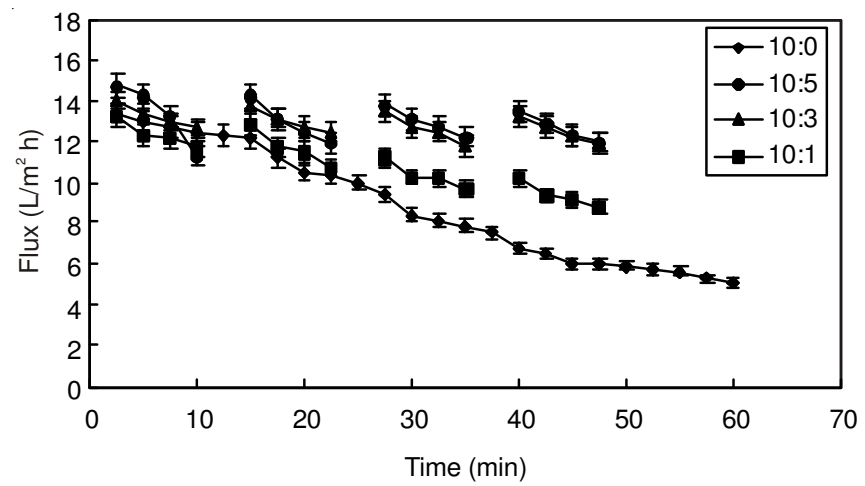

Fig. 3. Effect of cease time on membrane fouling

TABLE-1

QUALITY OF INFLOW IN TEST

\begin{tabular}{ccccccc}
\hline Items & Salinity $(\%)$ & $\mathrm{COD}(\mathrm{mg} / \mathrm{L})$ & Ammonia nitrogen $(\mathrm{mg} / \mathrm{L})$ & $\mathrm{TN}(\mathrm{mg} / \mathrm{L})$ & $\mathrm{PO}_{4}{ }^{3-}(\mathrm{mg} / \mathrm{L})$ & $\mathrm{SS}(\mathrm{mg} / \mathrm{L})$ \\
\hline Numerical value & $2-3$ & $770-1240$ & $103-191$ & $207-409$ & $21-48$ & $237-525$ \\
\hline
\end{tabular}


The decline tendency of cease time was 3 min have no significance to the $5 \mathrm{~min}$, but as the filtration periodic continuously, the membrane fouling rate could be controlled in a relative stable range. All these showed that intermittent water model can decrease the TMP and slow down membrane fouling effectively, but too extended cease time to hinder membrane fouling was not significant. During the process of filtration, the existence of negative pressure in the film leaded to the accumulation of solid particles on the membrane surface continuously. After filtration, own to the membrane silk jitter with aeration, the solid particle divorced from membrane surface and then membrane fouling was removed. When the filtration time and cease time reach a certain extent, empty aeration cannot remove the membrane fouling significantly, but decreased the water production and increased the energy consumption accordingly. Hence, a certain filtration and cease time can decrease the membrane fouling and recovered the membrane flux effectively, but it was unsuited when the filtration and cease time too long or too short. So it can be concluded that: the best suction and cease time of using ASBBR to treat mustard tuber wastewater were 10 and 3 min, respectively.

Effect of MLSS on membrane fouling: In the membrane filtration process, when the sludge concentration was high, more sludge particles, colloidal particles and dissolved macromolecular organics would exist in the sludge mixture, consequently, thicker cake layer would form on the membrane surface then caused the membrane resistance ramped ${ }^{27}$.

Fig. 4 depicted that membrane flux inverse to the MLSS under the same condition, the higher the MLSS was, the higher the decline rate of membrane flux would be, velocity of film resistance increased faster accordingly.

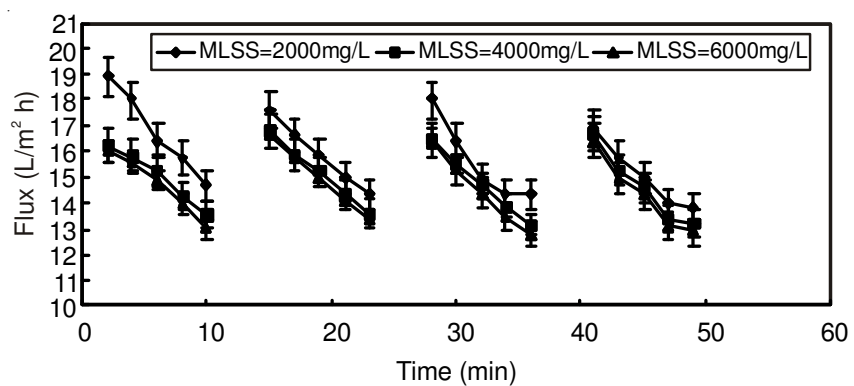

Fig. 4. Effect of MLSS on membrane fouling

When MLSS was high, solid particles plug the membrane hole and formed a compact cake layer, F/M declined, produced EPS in the reactor, increased the liquid viscosity, made the dewater ability of the sludge worsen and filtration resistance increasing. Instead, when MLSS was low, solid particles adsorption and accumulation in the film hole and membrane surface slowed down, leading to the slowing down of the formation speed of membrane hole blocking as well, then the filtration took the dominant position. Membrane resistance mainly came from the inherent resistance and growth of membrane hole blocked was slow accordingly. However, when the MLSS concentration was too low, the organics in the effluent could not be disassembled completely and also leaded to the existence of dissolved organics which were difficult to degrade in the supernatant of the reactor. So, suitable MLSS concentration can postpone the membrane fouling.

Hence, when the MLSS was $6000 \mathrm{mg} / \mathrm{L}$, the film hole blocking velocity was low and can make the organics disassembled efficiently.

\section{Conclusion}

The main single operation conditions affect the membrane fouling including TMP, suction and cease time, MLSS. Analysis showed that the best operation condition was the TMP, suction and cease time, MLSS were $15 \mathrm{kpa}, 3 \mathrm{~min}, 6000$ $\mathrm{mg} / \mathrm{L}$, respectively.

\section{ACKNOWLEDGEMENTS}

This study was supported by the National Natural Science Foundation of China (Grant No. 51008318) and the 111 project (Grant No. B13041).

\section{REFERENCES}

1. S.L. Yu and F.B. Zhao, Ind. Water Wastewater Chinese, 37, 1 (2006).

2. S. Adham, P. Gagliardo and L. Boulos, Water Sci. Technol., 43, 203 (2001).

3. R.M. Ben Aim and M.J. Semmens, Water Sci. Technol., 47, 1 (2003).

4. P.K. Park, S. Lee, J.-S. Cho and J.-H. Kim, Water Res., 46, 3796 (2012).

5. E.M.V. Hoek, A.S. Kim and M. Elimelech, Environ. Eng. Sci., 19, 357 (2002).

6. E. Huertas, M. Herzberg, G. Oron and M. Elimelech, J. Membr. Sci., 318, 264 (2008).

7. H. Hyung and J.-H. Kim, J. Membr. Sci., 286, 269 (2006).

8. J. Kaschemekat, W. Hilgendorff, K.W. Boddeker, A.M. Hassan and A.L.A. Malik, Desalination, 46, 151 (1983).

9. S. Kim, S. Lee, E. Lee, S. Sarper, C.-H. Kim and J. Cho, Desalination, 247, 162 (2009).

10. H. Koseoglu, N. Kabay, M. Yuksel, S. Sarp, O. Arar and M. Kitis, Desalination, 227, 253 (2008).

11. S. Lee, J. Cho and M. Elimelech, Desalination, 160, 1 (2004).

12. A. Malek, M.N.A. Hawlader and J.C. Ho, Desalination, 105, 245 (1996).

13. P.P. Mane, P.K. Park, H. Hyung, J.C. Brown and J.-H. Kim, J. Membr. Sci., 338, 119 (2009).

14. I.-S. Chang, P. Le Clech, B. Jefferson and S. Judd, J. Environ. Eng., 128, 1018 (2002).

15. I. Kang, S.-H. Yoon and C.-H. Lee, Water Res., 36, 1803 (2002).

16. K.H. Choo and C.H. Lee, Water Sci. Technol., 34, 173 (1996).

17. F.G. Meng, H. Zhang, F.L. Yang, S.T. Zhang, Y. Li and X. Zhang, Sep. Purif. Technol., 51, 95 (2006).

18. H. Hasar and C. Kinaci, Desalination, 170, 161 (2004).

19. H. Nagaoka, S. Ueda and A. Miya, Water Sci. Technol., 34, 165 (1996).

20. H. Choi, K. Zhang, D.D. Dionysiou, D.B. Oerther and G.A. Sorial, Chemosphere, 63, 1699 (2006).

21. J.A. Howell, J. Membr. Sci., 107, 165 (1995).

22. I.-S. Chang and S.J. Judd, Process Biochem., 37, 915 (2002).

23. P. Gui, X. Huang, Y. Chen and Y. Qian, Desalination, 151, 185 (2003).

24. Z.P. Cao, J.L. Zhang and H.W. Zhang, Ind. Water Treatment in Chinese, 28, 17 (2008)

25. J. Gutman, S. Fox and J. Gilron, J. Membr. Sci., 421-422, 1 (2012).

26. P. Gui, X. Huang, Y. Chen and Y. Qian, Desalination, 151, 185 (2003).

27. P. Le-Clech, V. Chen and T.A.G. Fane, J. Membr. Sci., 284, 17 (2006). 